\title{
Assessment of prevalence of work-related musculoskeletal disorders among welders in the shipyard industry in Malaysia
}

\author{
Anwar Johari ${ }^{1, *}$, Nurul Haznita Abdul Hamid ${ }^{2}$, Mohd Johari Kamaruddin ${ }^{1}$, Mimi Haryani Hassim ${ }^{1}$, Norzita \\ Ngadi $^{2}$, and Aishah Abdul Jalil ${ }^{1}$ \\ ${ }^{1}$ Centre of Hydrogen Energy, Institute of Future Energy, Universiti Teknologi Malaysia, 81310 Johor Bahru, Johor, \\ Malaysia. \\ ${ }^{2}$ School of Chemical and Energy Engineering, Faculty of Engineering, Universiti Teknologi Malaysia, 81310 Johor Bahru, \\ Johor, Malaysia. \\ *Corresponding author: anwar@utm.my
}

\begin{abstract}
Work-related musculoskeletal disorders (MSDs) are often experienced by welders in the shipyard industry. A study was conducted in one of the shipyards in Malaysia to identify the prevalence of work-related MSDs among welders and the factors attributed to its increase in the workplace. The investigation was carried out using a modified Nordic questionnaire, in which 27 shipyard welders were interviewed. The questions ranged from demographic information to the prevalence of MSDs on parts of body region experiencing discomfort and pain. The results showed that the most affected body regions were neck, upper back, and lower back, which comprised of $74.1 \%, 70.4 \%$, and $63.0 \%$, respectively, of the respondents being interviewed. A further in-depth study was conducted for the three most affected body regions with respect to work activities such as working posture, repetitive work, and lifting of heavy objects during welding. The frequency of prevalence of work-related MSDs on these body regions experienced by the welders showed that $25.9 \%$ of the respondents had frequently encountered neck pain and another $11.1 \%$ of them sometimes experienced discomfort while performing repetitive actions. The study also showed that $22.2 \%$ of the respondents sometimes experienced shoulder pain whereas $3.7 \%$ of them had reported to seldom encountered it when performing welding operation in awkward positions. Almost half of the respondents (i.e., $48.50 \%$ ) experienced discomfort and pain for both elbow/hand and wrist when lifting objects heavier than 5 $\mathrm{kg}$.
\end{abstract}

Keyword: Musculoskeletal disorders (MSDs), modified Nordic questionnaire, welding operation

\section{Introduction}

In Malaysia, workplace occupational diseases and poisoning have become one of the major issues in occupational safety and health. The increasing number of workers experiencing musculoskeletal disorders (MSDs) for the past few years has prompted numerous efforts by Department of Occupational Safety and Health (DOSH) and local universities to investigate causes of MSDs more extensively. There are many risk factors that could lead to MSDs, such as sustained exertion, contact stress, force, vibration, repetition work, handling loads, and others. It has also been reported that awkward working postures contributed to discomfort and injuries in one or various body parts such as neck, shoulder, back, elbow, hand, hip and knee, pain in the joints, tingling, and swelling [9]. In Malaysia, the statistical data on the reported cases of occupational work-related MSDs have shown an increasing trend from 1999 to 2009 as shown in Figure 1 [1]. 


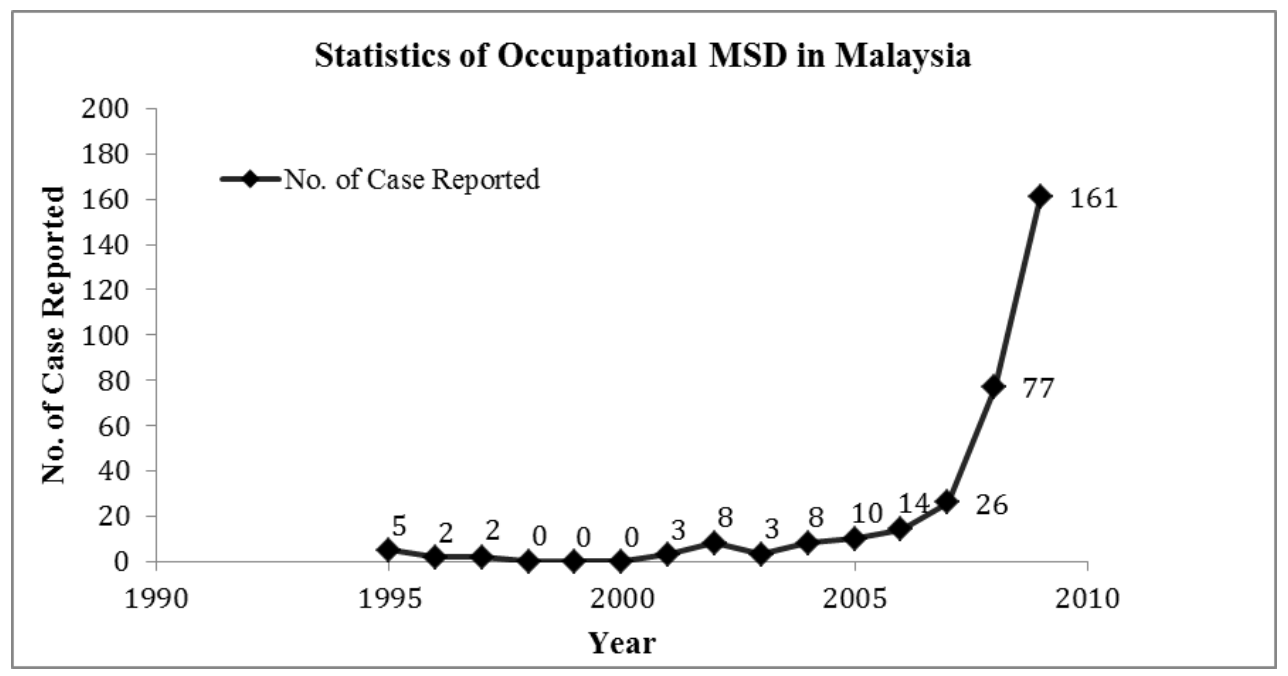

Fig. 1. Statistics of occupational MSDs in Malaysia.

In the shipyard environment, welding is routinely carried out and it is often associated with awkward postures, which are the contributing factors in MSDs among shipyard welders. Symptoms of MSDs among shipyard welders are prevalent in four body parts: hand, wrist, and fingers; arm and elbow; shoulder; and neck [2]. In the shipyard industry, shipyard workers are also involved in long hours of static work. Awkward postures, repetitive movements, and lifting of heavy objects are very common, and the majority of job activities are characterised by a sitting posture with the worker's head and trunk are flexed forward, and the shoulders are flexed and abducted. In this situation, the high rates of work-related MSD occurrences are expected to be experienced by the workers [3]. Despite the physical nature and work load commonly found in the shipyard industry, the prevalence of workrelated MSDs within shipyard workers in Malaysia has not received sufficient attention and priority. Neglecting the aspects of MSDs and ergonomics in the workplace somehow could affect work performance and the efficiency in terms of lost days due to absenteeism of the workers. Therefore, ergonomic studies and specifically work-related MSDs issues among workers become of great concern for most organisations. In line with the issues mentioned, a case study on the prevalence of MSDs among shipyard welders was carried out. Its findings are beneficial to identify and relate the risk factors in the workplace associated with welding operation. The study is important for organisations and to encourage early reporting of MSD symptoms experienced by welders. This study will be helpful for the shipping industry to evaluate their current progress in ergonomics, planning, training, and continuous improvement in order to prioritise the health and safety of welders in the shipyard industry.

\subsection{Background of the Case Study}

A leading shipyard company was selected for this study. The company provides integrated solutions for both marine and oil and gas industries in the Asia Pacific region. The company offers wide ranges of reliable services and facilities including shipbuilding, ship repair and maintenance, overhaul services for naval and paramilitary vessels, as well as engineering and fabrication of oil and gas facilities.

\section{Methodology}

Quantitative research method was used through the distribution of questionnaires and supported by interview sessions with 27 welders at the study site. The study comprised of two parts:

Part A - Demographic Questionnaire

This part consists of respondents' information on gender, age, and years of work experience. Simple multiple choices of "Yes" or "No" questions were used. 
Part B - Modified Nordic Questionnaire

This part of the questionnaires requires respondents to choose the parts of the body that experienced pain or discomfort such as neck, back, upper, and lower limbs during the past 12 months. In addition, the questionnaire includes diagrams of several awkward work postures, as well as questions on the repetitive nature and frequency of work and lifting of objects.

\section{Results and discussions}

\subsection{Demographic and working experience of respondents}

All respondents were male with most of them aged between 21 and 40 years old. Most of the respondents have been involved in the shipyard industry for two to five years. The data on demographic and working experience of the respondents are shown in Table 1.

Table 1. Demographic and working experience of respondents.

\begin{tabular}{|c|c|c|}
\hline Age & No. of Respondents & Percentage (\%) \\
\hline$\leq 20$ years old & 3 & 11.1 \\
\hline $21-30$ years old & 13 & 48.1 \\
\hline $31-40$ years old & 11 & 40.7 \\
\hline$\geq 41$ years old TOTAL & - & 100 \\
\hline Working Experience (years) & 27 & 18.5 \\
\hline$\leq 1$ & 5 & 70.5 \\
\hline $2-5$ & 19 & 11.1 \\
\hline $6-9$ & 3 & - \\
\hline$>10$ & - & 100 \\
\hline
\end{tabular}

\subsection{Prevalence of work-related MSDs among respondents}

The prevalence of work-related MSD symptoms based on modified Nordic questionnaire on body regions is shown in Table 2. The most affected body regions were neck, upper back, and lower back with 74.1\%, 70.4\%, and $63.0 \%$ of the respondents, respectively, experienced discomfort and pain during the past 12 months. These body regions were mostly affected by MSDs among the respondents due to their awkward working postures, heavy lifting of objects, and repetitive nature of welding operation. Welders in the shipyard industry reported a high prevalence of musculoskeletal complaints including neck pain and back injuries [4]. The results on the prevalence of work-related MSDs on body regions of the respondents are shown in Table 2.

Table 2. Prevalence of work-related MSDs among shipyard workers.

\begin{tabular}{|l|c|}
\hline \multicolumn{1}{|c|}{ Body Region } & Percentage (\%) \\
\hline Neck & 74.1 \\
\hline Shoulder (left) & 33.3 \\
\hline Shoulder (right) & 44.4 \\
\hline Elbow/hand (left) & 48.1 \\
\hline Elbow/hand (right) & 59.3 \\
\hline Wrist (left) & 40.7 \\
\hline Wrist (right) & 18.5 \\
\hline Hip/thigh/buttock (left) & 33.3 \\
\hline Hip/thigh/buttock (right) & 48.1 \\
\hline Knee (left) & 25.9 \\
\hline Knee (right) & 25.9 \\
\hline Ankle/feet (left) & 22.2 \\
\hline Ankle/feet (right) & 14.8 \\
\hline Upper back & 70.4 \\
\hline Lower back & 63.0 \\
\hline
\end{tabular}


A detailed study was conducted for the three most affected regions in body, namely neck, upper back, and lower back with respect to work activities normally associated with MSDs in welding operation. The three high risk factors are repetitive works, awkward postures, and lifting of heavy objects. The frequency of prevalence of work-related MSDs on body regions experienced by the welders due to repetitive works, awkward working postures, and heavy lifting activities is shown in Table 3.

Table 3: Frequency of work-related MSDs on neck, upper back, and lower back.

\begin{tabular}{|l|c|c|c|}
\hline Body Region & \multicolumn{3}{|c|}{ Work Activity } \\
\hline & Repetitive Works & Awkward Postures & Heavy Lifting \\
\hline Neck & $22.6 \%$ & $16.1 \%$ & $35.4 \%$ \\
\hline Upper Back & $19.2 \%$ & $19.2 \%$ & $32.0 \%$ \\
\hline Lower Back & $21.0 \%$ & $12.0 \%$ & $30.0 \%$ \\
\hline
\end{tabular}

These risk factors contributed significantly to symptoms in MSDs on those parts of the body regions. Heavy lifting of objects in welding operation was the main cause of discomfort and pain among the respondents. Indepth assessments of the three risk factors were carried out on neck, shoulder, and elbow and wrist. The findings showed that $25.9 \%$ of the respondents frequently encountered neck pain and another $11.1 \%$ of them sometimes experienced discomfort while performing repetitive actions. The frequency of neck pain and discomfort experienced by the respondents doing repetitive works is shown in Table 4. A past study has shown that repetitive actions for a very long static position contributed to neck pain [5].

Table 4. Frequency of neck pain for repetitive works.

\begin{tabular}{|c|c|c|}
\hline Neck Pain & \multicolumn{2}{|c|}{ Repetitive Works } \\
\hline & Yes (\%) & No (\%) \\
\hline Seldom & - & - \\
\hline Sometimes & 11.1 & 51.9 \\
\hline Frequent & 25.9 & 11.1 \\
\hline Always & - & - \\
\hline TOTAL & 37 & 63 \\
\hline
\end{tabular}

Awkward postures have been identified as one of the contributing factors in MSDs among the shipyard welders. It has been reported that awkward working postures have caused shoulder and body pain, largely due to the bending positions required for certain tasks [6]. The study shows that $22.2 \%$ of the respondents sometimes experienced shoulder pain whereas $3.7 \%$ of them reported to seldom encountered it. These postures include outreached arms, kneeling, squatting, as well as awkward positions of neck and head. The study has also shown that any outreached arm, stress, and strain of shoulder due to working postures are the cause of shoulder pain [7]. The frequency of shoulder pain and discomfort experienced by the respondents while performing the job in awkward postures is shown in Table 5.

Table 5. Frequency of shoulder pain for awkward posture.

\begin{tabular}{|c|c|c|}
\hline Shoulder Pain & \multicolumn{2}{|c|}{ Awkward Posture } \\
\hline & Yes (\%) & No (\%) \\
\hline Seldom & 3.7 & - \\
\hline Sometimes & 22.2 & 70.4 \\
\hline Frequent & - & 3.7 \\
\hline Always TOTAL & - & - \\
\hline
\end{tabular}


There was a clear indication on the frequency of pain and discomfort among the welders upon lifting objects heavier than $5 \mathrm{~kg}$ during welding. The regions of body affected by lifting of objects were elbow/hand and wrist. Almost half of the respondents (48.50\%) experienced discomfort and pain for both elbow/hand and wrist when lifting objects heavier than $5 \mathrm{~kg}$. The frequency of elbow/hand and wrist pain and discomfort experienced by the welders while lifting heavy objects is shown in Table 6. A similar study also reported that shipyard workers performing intensified workload such as heavy lifting experienced upper extremities body pain including neck, shoulder, hand, and wrist [8].

Table 6. Frequency of elbow/hand and wrist pain for lifting heavy objects.

\begin{tabular}{|c|c|c|}
\hline Elbow, Hand, and Wrist Pain & \multicolumn{2}{|c|}{ Heavy Lifting > 5 kg } \\
\hline & Yes (\%) & No (\%) \\
\hline Seldom & 26.3 & 18.2 \\
\hline Sometimes & 14.8 & 33.3 \\
\hline Frequent & 7.4 & - \\
\hline Always TOTAL & - & - \\
\hline
\end{tabular}

\section{Conclusions}

This study has identified the prevalence of work-related MSDs among welders in the shipyard industry. Most of the respondents experienced high degree of discomfort and pain on three parts of the body, namely neck, upper back, and lower back. Work activities in the welding operation such as repetitive works, awkward postures, and lifting heavy objects contributed to the overall symptoms of MSDs among the welders. Appropriate ergonomic intervention is required to minimise work-related MSDs among the welders. It is important to avoid or minimise awkward working postures when performing welding operation such as outreached arms, squatting, and awkward positions of neck and head. A long static body position during welding should be avoided. Regular use of a foot rest could help in reducing MSD risk when standing for long periods. Administrative and work practice controls are important elements in ergonomics to reduce MSDs. This is to minimise the duration of continual exertion, repetitive motions, and awkward postures. Employers should design a job rotation system where employees rotate between jobs that focus on different muscle groups. Ergonomics issues should be the focus of every aspect of welding operation to ensure safety and health of welders in the shipyard industry.

\section{References}

[1] Department of Occupational Safety and Health, Malaysia (DOSH), Occupational Musculoskeletal Diseases Statistics 1999-2009.

[2] Park, B.C. et al., Risk Factors of Work-related Upper Extremity Musculoskeletal Disorders in Male Shipyard Workers: Structural Equation Model Analysis, Safety and Health at Work, 2010. 1(2): 124-133.

[3] Bevan, S., Economic impact of musculoskeletal disorders (MSDs) on work in Europe, Best Practice \& Research Clinical Rheumatology, 2015, 29(3): 356-373.

[4] van Wendel de Joode, B., A. Burdorf, and C. Verspuy., Physical load in ship maintenance: Hazard evaluation by means of a workplace survey. Applied Ergonomics, 1997. 28(3): 213-21.

[5] Park, B.C., et al., Risk Factors of Work-related Upper Extremity Musculoskeletal Disorders in Male Shipyard Workers: Structural Equation Model Analysis, Safety and Health at Work, 2010. 1(2): 124-133.

[6] Zein, R.M., et al., A Survey on Working Postures among Malaysian Industrial Workers, Procedia Manufacturing, 2015. 2: 450-459. 
[7] Roffey, D.M., et al., Causal assessment of awkward occupational postures and low back pain: results of a systematic review, Spine J, 2010. 10(1): 89-99.

[8] Torell, G., Å. Sandén, and B. Järvholm, Musculoskeletal disorders in shipyard workers, Occupational Medicine, 1988. 38(4): 109-112. 